\title{
Project Planning by Modified Gauss S-Curve
}

\author{
Vladimir Križaić and Dražen Hranj
}

Polytechnic of Međimurje in Čakovec, Čakovec, Croatia, vkrizaic@mev.hr, dhranj@mev.hr

Planning is the prediction of the future erfrmed most often by a gantt chart as a graphical representation of the activity with respect to the temporal abscissa component. In addition to the activity ordinates, there is also a cash-flow or S-curve given by the one-dimensional nonlinear equation. Today, there is a growing demand for two-dimensional or 3D modeling, including 3D planning through a vector cummulative S-curve. Monitoring the distribution of the situation on formerly realized projects creates an image of certain model behaviour of the 3D S-curve defined by the modified Gaussian curve. By developing fifteen project plans from the buildingconstruction industry and from the construction project through the Microsoft project, the discrete S-curve connects to the modified Gaussian S-curve (MGSC). Analyses are made that indicate the equivalence of the S-curves of plans and realization, which defines the function of the parameters $\lambda \mathrm{kv}$ and $b$ in the variable of investment amounts of projects. Therefore, modeling and simulating a new Gaussian curve-modified method creates an $\mathrm{nM}$ model for project development with the ability to optimize plans and an S-curve future projects and adjusting online technology.

(c) 2020 The Authors. Published by Budapest University of Technology and Economics \& Diamond Congress Ltd Peer-review under responsibility of the Scientific Committee of the Creative Construction Conference 2020.

Keywords: planning, cash flow, 3D modeling, modified Gaussian S-curve, optimization

\section{Introduction}

Every system, especially construction production, takes place in time-span units, and every natural process also takes place in time-span values. Predicting system behavior over time is called planning in the system. Physicists and structural engineers have long since discovered the distributions of the density function $[1,2,3,4]$ for a number of natural processare the Gaussian and Erlang distributions. Planning in construction is inevitable, but it still relies on a low engineering principle. Many construction engineers have tried to define the S-curve of the project polynomially so that, based on its uninterrupted continuous sequence, they can predict the further course of the project. After a statistical survey of the realization S-curve in Međimurje Graditeljstvo Company, as part of the doctoral study in the course Project Management, an equation called a modified Gaussian S-curve is revealed. It is almost identical to the practice discrete statistics. However, the problem is in the small sample, so the constants in the equation are insufficiently quantified. Therefore, research is continuing into other plans of the familiar regional construction companies, namely TEAM Čakovec, which is specialized in building construction, and CARIN specialized in building construction using robotic technology. Due to better definining of constants and the modified Gaussian curve based on planning data, it has been proven for the implementations of over a dozen of large projects to match the planned values with only small discrepancies. Based on these discrepancies, the first modified curve has been supplemented and it is yet to develop until stability. In addition, the planned data of the prefabricated elements producing construction company Tehnobeton and from the civil engineering company TEGRA were added to complete the set of construction activities. Today, research is interested in monitoring deviations from the plan, i.e. in creating intervals of the range of variations and in the standard deviation of the observed magnitude which also behaves according to the Gaussian curve. This provided for the main precondition for planning precision and reducing business risk. Past experiences 
prove the riskiness of projects, especially in the first cycles of implementing a new project. The contribution of the representation of the S-curve by the modified Gaussian curve in relation to the existing polynomial ones s revealed in its ability to define the probability statistics arising from the Gaussian curve as the most common distribution of natural events and thus of construction production as well; furthermore, the formula is iterative in the function of cost and time, so when contracting a deal, a situational financial scheme can be made immediately for the investor, who can create a monthly financial scheme without a plan and make arrangements with the bank within a specified period and with a certain amount of credit. The third industrial revolution, computerization, that is, the softwarization of business systems with new CAD tools, has contributed to innovations in technology and organization of enterprises, especially with the discovery of 3D or vector organization [5]. Such novelties with cyber equations of a plan-modified Gaussian S-curve with recurrent DSP equations create a cyber system $[6,7]$ that can be defined from any system by sensing and adjusting the system within time. The goal of MGSC is to create a project management (PM) simulation to define and regulate the system as precisely as possible, i.e. to automate a group of PM processes, to plan, execute and control the project quality.

\section{Planning of projects by linear models}

In many construction companies in the late 20th century and at the end of the Third Industrial Revolution, an integrated information system (IIS), or software for managing the entire business system on an Oracle relational database, was designed, designed on designer devenloper tools, which creates the comfort of managing all the data of medium and giant companies. . Global companies have already introduced their own Model Based Systems Engineering (MBSE) standard models [8], derived from a well-known IBM corporation. The Maris system is IIS or a possible module in Building information modeling (BIM) [9]. Other software packages such as SAP, Optima Primavera, Gala and the Critical Path Method (CPM) and CPM combinatorics have also appeared in the market [10]. They all have their advantages and disadvantages in terms of project management use. Microsoft Project took over the market and developed the CPM method into various graphical representations and outperformed all competitors with its simplicity and ease of connecting to other systems. The software is rich in various versions and capabilities, so an expert should devote a lot of time to the software package to take advantage of all its options options. Reports and overviews in the editor can be great, but then you need to provide each resource with its quantitative data, which is a big drawback; however, with the feedback link to IIS, it all works successfully.

The simplest variable for project planning and monitoring is money as a function of time, that is, a 2D Scurve. Thus, various authors have addressed the definition of the S-curve. Equations from source $[11,12]$ and equation (1) Ostojić-Škomrlj, Radujković define a S-curve by a nonlinear polynomial curve.

$$
\begin{aligned}
& Y_{i}^{v i s .}=-0,0643212823 \cdot x_{i}-0,0278540885 \cdot x_{i}^{2}+0,0016474856 \cdot x_{i}^{3}-0,000023498997 \cdot x_{i}^{4}+ \\
& 0,0000001165 \cdot x_{i}^{5}-0,0000000001 \cdot x_{i}^{6}
\end{aligned}
$$

Whereas, to model and simulate the development of robots in Japan, an exponential curve with a discrete constant (2) was elaborated (Fig. 1) [13].

$$
Y_{t}=\frac{539}{1+e^{-0,3033(t-19,1211)}}
$$



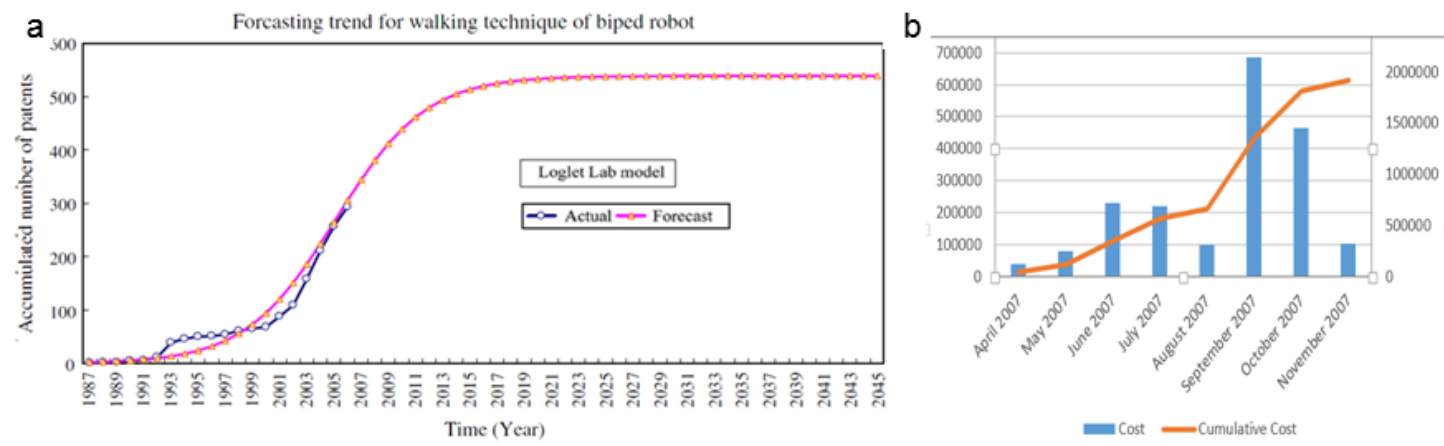

Fig. 1. (a) S-curve a) of the robots development in Japan [14]; (b) of a construction project (author).

The key problem of the given curves function is their one-dimensiona quality. This problem is solved by a modified Gaussian curve as it is in the function of two variables $x$ as an abscissa at time t shoving the months of production and ordinate $T$ as the cost variable or value of the investment.

\section{Planning the projects by a modified Gaussian curve from realisation plans}

Today's trend in informatics is the old mathematical method of numerical interpolation and approximation of functions, which has its root in mathematical algebra, that is, mathematical induction. The original definition of the S-curve by the Gaussian distribution function based on the bell-shaped event probability density function of the event shows a great coincidence in defining the S-curve. In MGSC [14], by replacing constant 2 in the fraction of power with a kv constant 10000, the so-called ironing of the S-curve function is instantly enhanced(3).

$$
s G t=\frac{1}{\sigma \cdot \sqrt{2 \cdot \pi}} \cdot e^{\frac{-(x-\mu)^{2}}{k v \sigma}}
$$

By introducing the constants $k v, \lambda k v$ and $a$ and $b$ as the coefficients of the equation of the standard deviation $\sigma$ (4) within the modified Gaussian S-curve (5), a high precision or a coincidence of the MGSC with the discrete S-curve of the realization plans was attained..

$$
\begin{aligned}
& \sigma=a \cdot T+b \\
& \operatorname{skvGr}(x, T)=\lambda k v \cdot \int_{0}^{x} \frac{1}{(a \cdot T+b) \cdot \sqrt{2 \cdot \pi}} \cdot e^{\frac{-(x-\mu)^{2}}{k v(a \cdot T+b)}} d x
\end{aligned}
$$

MGSC is a function of two cost variables $T$ and variable $x$, i.e., the time of the situation in month $t$, whereas the arithmetic mean or expectation of $\mathrm{x}$ is a constant $\mu$ corresponding to half of the project variable $\mathrm{x}$. The dispersion $\sigma$ has been replaced by the line in function of T. Thus we obtain an iterative equation or a recurrent equation having the variable $\mathrm{T}$ on both sides. Currently, probabilistic prediction of project performance and the use of stochastic S-curves by a software package to generate stochastic S-curves by a simulation approach shows the dispersion deviation [15] of the S-curve by the Gaussian function of the density of cost and time distribution (Fig. 2). However, the problem of the unidimensionality of these curves or 2D representations of functions remains.
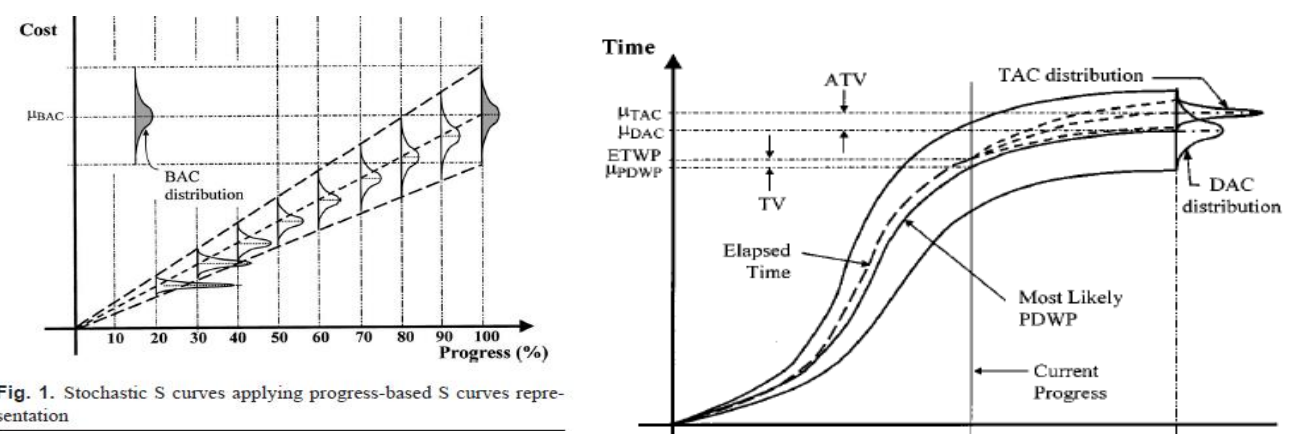

Fig. 2. Probabilistic dispersion of cost and time, in implementing a project [15] 


\section{Planning of projects by modified Gaussian S-curve from project planning}

Observing the Gantt charts of various MS projects over a couple of years for some completed projects shows that in the first part of the implementation time, the activity of constructions takes place and finally the equipping and finishing works on projects of new high-rise construction, whereas maintenance closes the circle when reconstructions in civil engineering are concerned (Fig. 3 ).

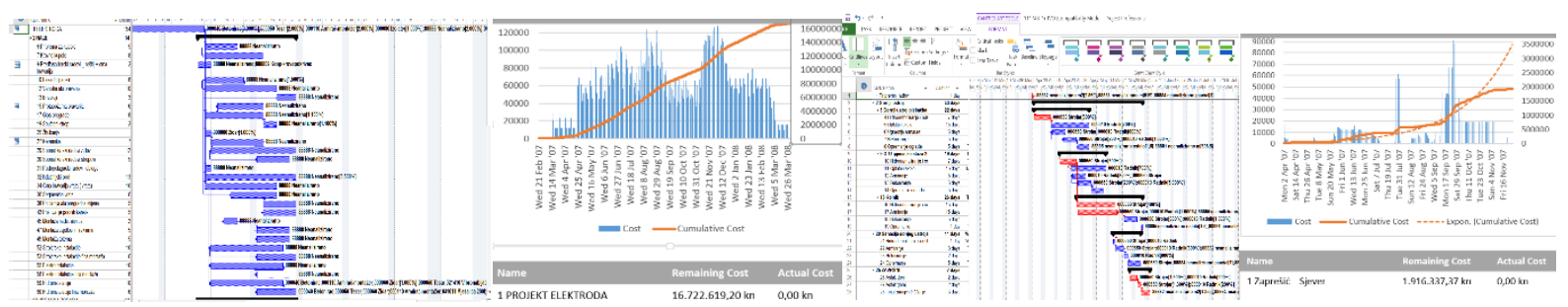

Fig. 3. TEAM - Elektroda Zagreb and the reconstruction of the bridge over the Sava at Zaprešić - CARIN Zagreb and a series $f$ characteristic plans with supremum and i infimum in the S.curve distribution (author)

The assumption is that a modified Gaussian curve can express all project plans. By considering the dimensions of the variables and constants before mentioned $(a, b, T, t, x, k v, \lambda k v, \mu)$ from the project plans of various authors and various construction activities, a certain dependence of variables is created in the increased interval of the value of variables in relation to the realized projects of Međimurje Construction . From thinned Table 1 it can be seen that the value of project $T$ is mainly in proportion to the variables $t, \lambda \mathrm{kv}$ and $b$ whereas the constant $a$ is constant and remains as in (4) and $t / 2$ replaces $\mu$ (table 1).

Table 1. The intervals of constants and variables in the MGSC dispersion of pians

\begin{tabular}{|c|c|c|c|}
\hline $\mathrm{T}=$ situiranje u 1000 & $\mathrm{t}$ & $\lambda \mathrm{kv}$ & $\mathrm{b}$ \\
\hline 393 & 4 & 0,055 & 0,0001 \\
\hline 10585 & 8 & 3 & 0,0004 \\
\hline 18486 & 5 & 8 & 0,0004 \\
\hline 18636 & 13 & 55 & 0,00075 \\
\hline 2878446 & 18 & 7000 & 0,0008 \\
\hline
\end{tabular}

The given intervals of variables of the modified Gaussian distribution allow the creation of an idealized planning S-curve proportionally - i.e. linearly - for given constants in relation to the value of the investment. Further iterative increments in activities in SMEs or resources optimize the plan of a project. However, these are not all the factors that affect the value of a project but they are among the leading variables. Creating a real curve equated to actual real data from the data distribution proves that the constant kv amounts 10000 and $\lambda \mathrm{kv}, \mathrm{a}$, and $\mathrm{b}$ are discrete values for each case that is in turn defined separately and discretely.

The planned values of the S-curve thus coincide with the realization plans of the projects addressed in the original survey. In the examples given, a discrete S-curve (kumR) was extracted and by ironing with variables a modified Gaussian curve, a (skvGrR) curve with a discrete graphical overlap was identified (Fig. 4). This proves the approximate value of the definition of an S-curve as a discrete polynomial and a functional modified Gaussian curve with actual project values (5). 


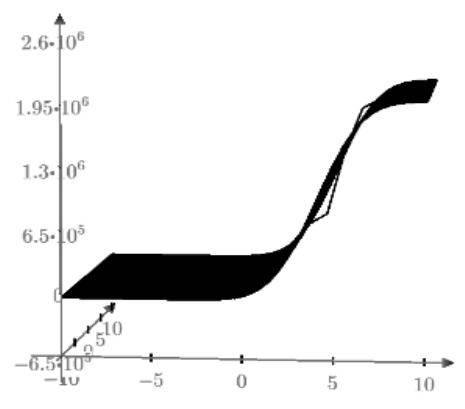

kumR

skvGrR

Fig. 4. Analytc ad graphic overview of Elektroda Zagreb project with the real discrete values (kumR) and modified Gaussian S-curve (skvGr, skvGrR) (author)

Another assumption is the automation of the MGSC design so that the parameter $\lambda \mathrm{kv}$ and $\mathrm{b}$ can be defined with a linear or parabolic function. From the data (Table 2) and (Fig. 5) it can be seen that the value of the project $T$ is mainly proportional to, i.e. linear with the variables $t$ and the parameters $\lambda k v$ and $b$, while the parameter a is constant remaining as in (4) whereas $t / 2$ replaces $\mu$.

Table 2. The intervals of constants and variables in the MGSC dispersion of Tehnobeton plans (similar. Tegra)

\begin{tabular}{|c|c|c|c|}
\hline $\mathrm{n}$ & $\mathrm{b}$ & $\lambda \mathrm{kv}$ & $\mathrm{T}$ \\
\hline 8 & 0,00075700 & 1,35 & 3220,00 \\
\hline 9 & 0,00075700 & 1,35 & 3200,00 \\
\hline 11 & 0,00075700 & 9,30 & 8150,00 \\
\hline 10 & 0,05000000 & 440,00 & 24830,00 \\
\hline
\end{tabular}

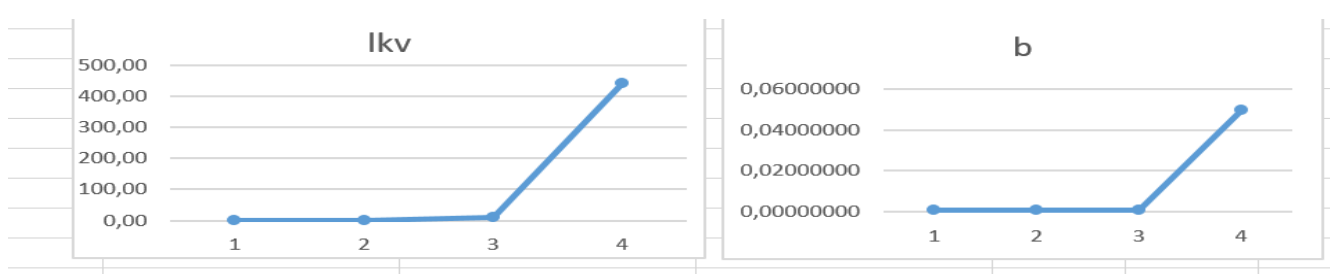

Fig. 5. Variables in function of $\mathrm{T}-$ amounts (author)

By elminating the extreme values, the parameter $\lambda \mathrm{kv}$ takes on the value of equation (6), which has yet to be supplemented with new research.

$$
\lambda k v=0.295+2.287 \cdot 10^{-4} \cdot T+7.982 \cdot 10^{-9} \cdot T^{2}
$$

An attempt to automate the MGSC equation with parameter $\lambda \mathrm{kv}$ partially satisfies the solutions whereas parameter $b$ does not behave in accordance with the examples given. Thus, parameter $b$ is still unexplored yet it does contribute in the exponential and the fraction, so it has a visible effect on the value of the equation.

\section{Conclusion}

The given equation is just a prototype for a real two-dimensional S-curve as a function of $\mathrm{T}$ (cost or situation or investment) and $x$ as a time variable t. More field data is needed to study the nonlinear models that are proposed and to define coefficients $a$ and $b$ with as much precision and probability as possible. In relation to the realization intervals of constants and variables, the MGSC from the plan data creates an extension of the intervals of variables and constants with proportional dependence. Further elaboration and use of curve data as limiting conditions over activities creates a new area of optimization in activity-level planning 
as a project differentiator. Therefore, as a by-product, the optimal density of the modified Gaussian curve can be defined, which also achieves the optimal $\sigma$ or standard deviation of the project plan. For the safety and precision of the given hypotheses, it is necessary to have an appropriate database used to determine the probability distribution, that is, to provide a direct calculation of the impact of the risk on the duration, cost and quality of the project $[16,17]$. MGSC is therefore in function of two variables $T$ and $t$, cost and time, respectively. Creating a real curve equated to the actual real data from the data distribution proves that the constant $\mathrm{kv}$ in the amount of 10000 does not change, and $\lambda \mathrm{kv}$ is defined by the equation that approximates the values of the S-curve to the given models. The approximate parameter $\lambda \mathrm{kv}$ is a landmark for faster selection of MGSC. The disadvantage is that attempting to prove the parameter $b$ functionally with $\mathrm{T}$ did not give the desired effect, so there is no an automatic definition of the S-curve, but b has to be assigned manually as the initial condition until parameter $\mathrm{b}$ satisfies the $\mathrm{S}$-curve. It is expected that a more accurate forecast of project planning is to be created and that it is to define a more precise deviation, i.e. plan dispersion and realization. Thus defining the general equation of the S-curve in a multidimensional space gives the whole set of S-curves as the supremum and infimum of the data set in a project. This in turn creates a probability area using statistical curves, so better risk management is possible in the project [18] terefore online technology. Conversely, it also provides production management with a premised MGSC, which opens a new field of research. Further research is recommended that will relieve the present lack of MGSCs in realization as there is no shift in the cost variable due to a shift in the time variable. Thus, not only project planning should be defined but the equation of MGSC simulations at the time of project realization as well. Accordingly, the new equation can lead to simulation based on MGSC differential equations, which is similar to the finite element analysis of ANSYS software [19] that is in turn based on numerical mathematics [20] just like MGSC itself.

\section{References}

[1] Ž. Pauše, Vjerojatnost informacija - stohastički procesi, Školska knjiga, Zagreb, (1988)

[2] S. Vukadinović, Elementi teorije verovatnoće i matematičke statistike, NIGRO - Privredni pregled, Beograd, (1978)

[3] P. Newbold, W. Carlson, B. Thorne, Statistika za poslovanje i ekonomiju, Copyryght - MATE, Zagreb, (2010)

[4] Z. Ivković, Matematička statistika, Naučna knjiga, Beograd, (1980)

[5] V. Križaić, D. Hranj, VECTORAL ORGANIZATION OF CONSTRUCTION BUSINESS SYSTEM, Technology and management in Construction, 10th International Conference Organization, Šibenik, (2011)

[6] Bonci, A. Carbonari, A. Cucchiarelli, L. Messi, M. Vaccarini, A cyber-physical system approach for building efficiency monitoring, International Research Journal Automation in Construction, Vol. 102, No. 6, pp. 68-85, (2019), https://doi.org/10.1016/j.autcon.2019.02.010

[7] L. Monostori, B. Kádár, T. Bauernhansl, S. Kondoh, S., Kumara, G. Reinhart, O. Sauer, G. Schuh, W. Sihn, K. Ueda, Cyber-physical systems in manufacturing, CIRP Annals - Manufacturing Technology, Vol. 65, No. 2, pp. 621-641, (2016), https://doi.org/10.1016/j.cirp.2016.06.005

[8] E. Jeff, Survey of Model-Based Systems Engineering (MBSE) Methodologies, INCOSE MBSE Focus Group, Vol. 25, (2008)

[9] E. Elbeltagi, O. Hosny, M. Dawood, A. Elhakeem, BIM-Based Cost Estimation/ Monitoring For Building Construction, Journal of Engineering Research and Applications, Vol. 4, No. 7, pp. 56-66, (2014)

[10] V. Križaić, PLANNING THROUGH COMBINATORICS, Organization, tehnology and management in construction, University of Zagreb, Faculty of Civil Engineering, Croatian Association for Construction management, 2006

[11] N. Ostojić-Škomrlj, M. Radujković, Model prognoziranja S-krivulja u ranim fazama građevinskih projekata, Građevinar, Vol 64, No 8, pp. $647-654$. ., (2012)

[12] A. Kaka, J. Lewis, Development of a company-level dynamic cash flowforecasting model (DYCAFF), Construction Management and Economics, Vol. 21, No. 7, pp. 693-705, (2003), https://doi.org/10.1080/0144619032000116561

[13] C.Y. Liu, J.C. Wang, Forecasting the development of the biped robot walking technique in Japan through S-curve model analysis, Published online Akademiai Kiado Budapest, Hungary, (2009)

[14] V. Križaić, D. Hranj, Project Management by Modified Gaussian S-curve, Trust in Major \& Mega Projects, Ivica Završki, ANITA Cerić, Mladen Vukomanović, Marina Huemannn, Ding Ronggui, University of Zagreb, Faculty of Civil Engineering, Croatian Association for Construction management, (2019)

[15] A.G. Barraza, W.E. Back, F. Mata, Probabilistic Forecasting of Project Performance Using Stochastic S Curves, JOURNAL OF CONSTRUCTION ENGINEERING AND MANAGEMENT, downloaded from ascelibrary.org by University Of Zagreb Faculty Of Civil Engineering, pp 25-32, (2004)

[16] F.H. Abanda, B. Kamsu-Foguem, BIM - New rules of measurement ontology for construction cost estimation, Engineering Science and Technology, an International Journal, Vol. 20, No. 2, pp 443-459, (2017), https://doi.org/10.1016/j.jestch.2017.01.007

[17] D. D. Wu, X. Kefan, C. Gang, G. Ping, A Risk Analysis Model in Concurrent Engineering Product Development, Risk Analysis, Vol. 30, No. 9, pp.1440-53, (2010), https://doi.org/10.1111/j.1539-6924.2010.01432.x

[18] Burcar-Dunovic, M. Radujkovic, M. Vukomanovic, Internal and external risk based assessment and evaluation for the large infrastructure projects, Journal of Civil Engineering and Management, Vol. 22, No. 5, pp. 673-682., (2016)

[19] A. Mahmood, R.A. Al-Samarai, N.A. Fadhil, Comparative Study on Mechanical Properties of Steel by Numerical Analysis and Experimental Tests, (2019), https://doi.org/10.4206/aus.2019.n26-25

[20] Ivanšić, Numerička matematika, Element, Zagreb, (1998) 